\title{
ANTI-NUCLEAR ANTIBODY (ANA) PATTERNS IN EGYPTIAN SYSTEMIC LUPUS ERYTHEMATOSUS
}

By

AZZA M. ELAMIR ${ }^{*}$, ALYAA A. FARID ${ }^{1}$, ESRAA S. AMIN ${ }^{2}$, HEBA A. HASSAN ${ }^{2}$, MOHAMED M. MAGED ${ }^{2}$, and AHMED A. AREF ${ }^{2}$,

Department of Zoology, Faculty of Science, Cairo University ${ }^{1}$ and

Faculty of Biotechnology, October University for Modern Sciences and $\operatorname{Arts}^{2}$ (MSA), $6^{\text {th }}$ October City, Giza, Egypt ( ${ }^{*}$ Correspondence: azzaelamir@yahoo.com)

\section{Abstract}

In fact autoantibodies are immunoglobulins against self-antigens that are known as endogen antigens. Systemic lupus erythematosus (SLE) is an occasion that the body begins a fight against its own cells and organs. There are different types of autoantibodies that have been identified in recent years. The most familiar is anti-nuclear antibodies (ANA). They are created against cell nuclei, and one of the methods used for its detection and its pattern determination is indirect immunofluorescence test (IIF). IIF was used for that purpose in our study, and concluded that ANA positivity rate was higher in female patients than the male ones, where ANA was positive in $36.1 \%$ of the male patients and $48.2 \%$ of female patients. Also, the most frequent ANA patterns in SLE patients were speckled pattern, where $21.6 \%$ \& $41.3 \%$ of male and female patients, respectively, have speckled pattern of ANA.

Key words: Egypt, Systemic lupus erythematosus, Anti-nuclear antibody

\section{Introduction}

Systemic lupus erythematosus (SLE) is a multisystem heterogeneous autoimmune disorder with wide clinical and laboratory manifestations (D'Cruz et al, 2007). SLE is characterized by exacerbations and remissions, with development of new organ manifestations or progression of existing manifestations (Petri, 2007). Previous studies have reported the clinical features of SLE based on sex, age at the disease onset, individual autoantibody prevalence and autoantibodies clusters (Cojocaru et al, 2011).

Fawzy et al. (2016) in Egypt reported that SLE is a multisystem involvement, includeing the gastrointestinal (GI) tract, with a significant variation in the clinical presentation and severity of GI disorders. Such autoantibodies are immunoglobulins, but are targeted against self-antigens known as endogenous protein antigens. The self-antigens might be enzymes, cell receptor, phospholipids and nucleic acids (Muro et al, 2005). Anti-nuclear antibodies (ANA) are created against own cell nucleus proteins. Several studies tried to explain how the body-fight itself; it was reported that this may be due to infection, environmental factors or genetical link. These autoantibodies interfere in many SLE manifestations (Heffernan et al, 2001; Fritzler et al, 2003; Muro et al, 2005). The detection of autoantibodies in serum samples of patients plays an important role in diagnosis and in follow-up of the disease in recent years. IIF has been used as a screening test for these autoantibodies, especially for determination of anti-nuclear antibodies (Yumuk et al, 2005).

The present study aimed to determine the ANA rate positivity and its patterns in the Egyptian SLE patients using indirect immuno-fluorescence test (IIF), regarding the sociodemographic characters of SLE patients.

\section{Materials and methods}

Patients and ANA tests: ANA test results of 300 patients with SLE were selected from the out patients clinics of El-Monira Public Health Hospital and evaluated retrospectively. ANA test (HEp 20-10, EUROIMMUN, Germany) was used in dilution of 1:100 in IIF test (Mengeloglu et al, 2014). The slides were prepared according to the instructions of the manufacturer and evaluated under the fluorescence microscope using $40 \mathrm{X}$ objective. Intensity of fluorescence was interpreted semi quantitatively based on negative co- 
ntrol (0) and positive control $(+4)$.

This study was approved by the $\mathrm{MOH}$ Ethics Committee and a signed informed consent was obtained from all the participants.

The included patients underwent regular follow-up for the medical history, physical examination, clinical manifestations and laboratory examinations. Patients who fulfilled at least four of The American College of Rheumatology (ACR) criteria for the SLE classification (Hochberg, 1997) were included.

Statistical analysis: Data were analyzed using IBM SPSS Statistics Version 15.0 (SPSS Inc., Chicago, IL, United States). Descriptive variables were given as numbers and percentages.

\section{Results}

Amongst 300 tests, 290 (96.6\%) resulted as
ANA positive. The mean age was $40.8 \pm 5.6$ in ANA-positive patients and was 39.3 \pm 11.6 in ANA-negative individuals. Amongst the patients, $97(32.3 \%)$ were males and 203 $(67.6 \%)$ were females. ANA was positive in $35(36.1 \%)$ of the males and $98(48.2 \%)$ of females; accordingly ANA positivity rate was higher in female patients than the male ones. The most frequent ANA patterns were speckled pattern $(21.6 \% \& 41.3 \%$ for male and female patients respectively). The ANA levels in SLE patients $(2.92 \pm 1.0)$ were significantly higher than that $(0.53 \pm 0.23)$ in healthy control group. In SLE patients, the highest value for ANA secretion was 5.51 $\mathrm{IU} / \mathrm{ml}$ and the lowest value was $1.95 \mathrm{IU} / \mathrm{ml}$ with a range 3.56. Details were given in tables $(1,23 \& 4)$

Table 1: Socio-demographic characteristics of SLE patients.

\begin{tabular}{|l|c|c|}
\hline Item & Number & $\%$ \\
\hline Age in years: & & \\
$20-30$ & 147 & $49 \%$ \\
$31-45$ & 153 & $51 \%$ \\
\hline Sex: & & \\
Male & 97 & $32.3 \%$ \\
Female & 203 & $67.6 \%$ \\
\hline Marital status: & 279 & \\
Single & 21 & $93 \%$ \\
Married & & $7 \%$ \\
\hline Educational level: & 14 & \\
Illiterate & 39 & $4.6 \%$ \\
Write and read & 190 & $13 \%$ \\
Moderate & 57 & $63.3 \%$ \\
High & & $19 \%$ \\
\hline
\end{tabular}

Table 2: Median and range of ANA concentration ( $\mathrm{pg} / \mathrm{ml})$ in SLE patients and healthy controls.

\begin{tabular}{|l|l|l|l|l|l|l|}
\hline & Group & Median & Mode & Lowest value & Highest value & Range \\
\hline ANA & SLE patients & 2.64 & 0 & 1.95 & 5.51 & 3.56 \\
\cline { 2 - 7 } & Control & 0.54 & 0.21 & 0.1 & 0.87 & 0.77 \\
\hline
\end{tabular}

Table 3: $P$ value for concentration of ANA in SLE patients and healthy controls.

\begin{tabular}{|l|l|l|l|}
\hline Parameters & Control $(\mathrm{M} \pm \mathrm{SD})$ & SLE patients(M \pm SD) & $P$ value \\
\hline ANA & $0.53 \pm 0.23$ & $2.92 \pm 1.0^{*}$ & 0.04 \\
\hline
\end{tabular}

*Significant difference $(\mathrm{P}<0.05)$.

Table 4: ANA pattern in male and female Egyptian patients.

\begin{tabular}{|l|l|l|}
\hline ANA pattern & Male patients & Female patients \\
\hline Speckle & $21(21.6 \%)$ & $84(41.3 \%)$ \\
\hline Nucleolar & $4(5 \%)$ & $5(2.4 \%)$ \\
\hline Homogenous & $8(8.2 \%)$ & $7(3.4 \%)$ \\
\hline Perinuclear & $1(1 \%)$ & $2(0.98 \%)$ \\
\hline
\end{tabular}




\section{Discussion}

The SLE is a chronic autoimmune inflammatory disease that can harm any organ of the body. The production of ANA was the prominent character of the disease. Diagnosis is based on differential clinical and laboratory markers, after eliminating other cross skin diseases. SLE classification criteria are used as a guide to help in identification of salient clinical characters when making the diagnosis. Serological findings are criteria in suggesting SLE (Riemakasten and Hiepe, 2013).

ANA test is used as a serologic marker for several autoimmune diseases. ANA are immunoglobulins that bind to antigens expressed within the human cells' nucleus. The most common used test for measuring ANA are indirect immunofluorescence antinuclear antibody test (IF-ANA) and ELISA (Marin et al, 2009).

A significant test in diagnosis of autoimmune diseases was indirect immunofluorescence test (IIF). This test can be used in determination of ANA pattern leading to excellent differential diagnosis (Yumuk et $a l, 2005)$. ANA test has advantage as easiness and low cost, however it need experienced staff to be performed. Also, ANA test has low sensitivity and specificity. Clinicians may be in the need IIF results to support ANA results (Yilmaz et al, 2001).

The prevalence of positive ANA in SLE was $90-100 \%$ and this autoantibodies prevalence differed between different races (Kasitanon et al, 2004). Wichainun et al. (2013) reported that ANA and anti-dsDNA gave high sensitivity and high specificity in SLE patients, even when using sera of patients with multiple medical problems as controls. According to the present results, ANA levels in SLE patients $(2.92 \pm 1.0)$ were significantly higher than that $(0.53 \pm 0.23)$ in the healthy control group. Also, in SLE patients, the highest value for the ANA secretion was $5.51 \mathrm{IU} / \mathrm{ml}$ and the lowest value was 1.95 $\mathrm{IU} / \mathrm{ml}$ with a range 3.56 .

SLE is known to be less prevalent in males than in females, but the reason for this sexual predilection is still controversies. However, much argument surrounds the differences in complication of the disease in both sexes. Nevertheless, Yacoub Wasef (2004) reported the elevated SLE frequency among females may be due to differences in the sex hormones' metabolism and/or the GnRH. Although, SLE is less common in males, it tends to be more severe. The author recommended the regular follow-up of the SLE male patients. These findings agreed with the present results, where ANA test was positive in $36.1 \%$ of males patients and $48.2 \%$ of females; accordingly the ANA positivity rate was higher in female patients than the male ones.

In the present study, ANA positivity rate and ANA patterns in male and female Egyptian SLE patients were evaluated. The most frequently reported patterns were speckled, nucleoli and homogenous patterns. The speckled pattern was $21.6 \%$ and $41.3 \%$ for male and female patients respectively. $5 \%$ of male patients and $2.4 \%$ of female patients have nucleolus pattern. Also, 8.2\% of male patients and $3.4 \%$ of female patients have homogenous pattern. The lowest percent was observed with perinuclear pattern, $1 \%$ and $0.98 \%$ for male and female patients respectively. The present results agreed with Peene et al. (2001) who found that the commonest one was speckled patterns. Yilmaz et al. (2004) reported homogenous pattern in more than half of their patients. Mengeloglu et al. (2014) found a significant association between ANA positivity and SLE, as the most frequent ANA patterns were coarse speckled pattern in patients were (154 or $31.2 \%$ ), nucleolar pattern (89 or $18.0 \%$ ), fine speckled pattern (57 or 11.5\%), and speckled (granular) pattern (48 or $9.7 \%$ ).

No doubt, ANA test was positive in connective tissue disorders, however, it was added that ANA positivity was not absolutely diagnostic. The ANA positivity could be observed in $95 \%$ in SLE and mixed connective tissue disorders, and that this rate 
could be between $25-70 \%$ cases with the Sjögren syndrome, systemic sclerosis and RA (Fritzler et al, 2003, Muro, 2005).

\section{Conclusion}

The data showed that ANA test was positive in female patients than males, ANA testing proved sensitive in screening SLE, speckled pattern was $21.6 \%$ \& $41.3 \%$ for male and female patients respectively and $5 \%$ of males and $2.4 \%$ of females showed nucleolus pattern. Also, $8.2 \%$ of males and $3.4 \%$ of females had homogenous pattern. The lowest percent was with per-nuclear pattern, $1 \%$ and $0.98 \%$ for males and females respectively.

\section{Acknowledgements}

Many thanks are due to the authorities of El-Monira Public Health Hospital for facilitating this work. Thanks are also due to the Head Authorities of Faculty of Biotechnology, MSA University.

Special thanks are extended to Dr. Nahla M. Shoukry, Professor of Immunology and Parasitology, Faculty of Science, Suez University for kindly critical revising this manuscript

\section{References}

Cojocaru, M, Cojocaru, IM, Silosi, I, Vrabie, CD, 2011: Manifestations of systemic lupus erythe-matosus. Medicine (Buchar). 6:330-6.

D'Cruz, DP, Khamashta, MA, Hughes, GR, 2007: Systemic lupus erythematosus. Lancet 369:587-96.

Fawzy, M, Edrees, A, Okasha, H, El Ashmaui, A, Ragab, G, 2016: Gastrointestinal manifestations in systemic lupus erythematosus. Lupus. 25, 13:1456-62

Fritzler, MJ, Wiik, A, Fritzler, ML, Barr, SG, 2003: Use and abuse of commercial kits used to detect autoantibodies. Arthritis Res. Ther. 5:192201.

Heffernan, MP, Do, JH, Mehta, J, 2001: Antinuclear antibodies in dermatology. Semin. Cut- an. Med. Surg. 20, 1:2-13.

Hochberg, MC, 1997: Updating the American College of Rheumatology revised criteria for the classification of systemic lupus erythematosus. Arthritis Rheum. 40:1725-9.

Kasitanon, N, Louthrenoo, W, Sukitawut, W, Vichainun, R, 2002: Causes of death and prognostic factors in Thai patients with systemic lupus erythematosus. Asian Pac. J. Allergy Immunol. 20:85-91.

Marin, GG, Cardiel, MH, Cornejo, H, Viveros, ME, 2009: prevalence of antinuclear antibodies in 3 groups of healthy individuals. J. Clin. Rheumatol. 15:325-9

Mengeloglu, Z, Tas, T, Kocoglu, E, Aktas, G, Karabörk, S, 2014: Determination of anti-nuclear antibody pattern distribution and clinical relationship. Pakis. J. Med. Sci. 30:380-3.

Muro, Y, 2005: Antinuclear antibodies. Autoimmunity 38, 1:3-9

Peene, I, Meheus, L, Veys, EM, De Keyser, F, 2001: Detection and identification of antinuclear antibodies (ANA) in a large and consecutive cohort of serum samples referred for the ANA testing. Ann. Rheum. Dis. 20:1131-6.

Petri, M, 2007: Monitoring systemic lupus erythematosus in standard clinical care. Best Pract. Res. Clin. Rheumatol. 21:887-97.

Riemakasten, G, Hiepe, F, 2013: Autoantibodies. In: Dubois' Lupus Erythematosus and Related Syndromes, 8, Wallace, DJ and Hahn, BH (Ed.), Elsevier Saunders, Philadelphia.

Wichainun, R, Kasitanon, N, Wangkaew, S, Hongsongkiat, S, Sukitawut, W, Louthrenoo, W, 2013: Sensitivity and specificity of ANA and anti-dsDNA in the diagnosis of systemic lupus erythematosus: a comparison using control sera obtained from healthy individuals and patients with multiple medical problems. Asian Pac. J. Aller. Immunol. 31, 4:292-8.

Yacoub Wasef, SZ, 2004: Gender differences in systemic lupus erythematosus. Gend. Med. 1, $1: 12-7$.

Yilmaz, Ö, Karaman, M, Ergon, MC, Bahar, IH, Yulug, N, 2004: Comparison of indirect immunofluorescence and enzyme immunoassay methods for the determination of antinuclear antibodies. Mikrobiyol. Bul. 38:85-90.

Yilmaz, Ö, Karaman, M, Kosar, Y, Bahar, I H, Yulug, N 2001: The comparison of indirect immunofluorescence, enzyme immunoassay and western blot methods for the detection of the antinuclear antibodies. Mikrobiyol. Bul. 35:47380.

Yumuk, Z, Caliskan, S, Gündes, S, Willke, A, 2005: Investigation of the antinuclear antibodies (ANA) and techniques for detection. Türk. Mikrobiyol. Cem. Derg. 35, 1:40-4 